\title{
Crack prediction in beam-like structure using ANN based on frequency analysis
}

\author{
Seguini Meriem, Nedjar Djamel \\ University of Sciences and Technology of Oran Mohamed Boudiaf USTO-MB, Bp 1055 EL Menaour, Oran 31000, Algeria \\ Laboratory of Mechanic of Structures and Stability of Constructions LM2SC, Faculty of Architecture and Civil Engineering \\ meriem.seguini@univ-usto.dz; bttps://orcid.org/0000-0003-1985-3129 \\ djamel.nedjar@univ-usto.dz.
}

\section{Boutchicha Djilali}

University of Sciences and Technology of Oran Mohamed Boudiaf USTO-MB, Algeria

LMA, Mechanical Engineering Department,USTO-MB, Bp 1055 EL Menaour, Oran 31000, Algeria

djilali.boutchicha@gmail.com

\section{Samir Khatir, Magd Abdel Wahab}

Soete Laboratory, Faculty of Engineering and Architecture, Ghent University, TechnologieparkZwijnaarde 903, B-9052 Zwijnaarde, Belgium

Khatir.samin@hotmail.fr; bttps:/ / orcid.org/0000-0002-8101-3633

Magd.AbdelWahab@UGent.be; https://orcid.org/0000-0002-3610-865X

\begin{abstract}
The dynamic experimental and numerical analysis of cracked beams has been studied with the aim of quantifying the influence of depth crack on the dynamic response of steel beams. Artificial Neural Method ANN has been used where a numerical simulation was improved in Matlab. A finite element model has also been developed by using the Ansys software, and the obtained results were compared with exact crack length. The study takes into account different hidden layer values in order to determine the sensitivity of the predicted crack depth. The results show that the response of the beam (frequencies) is strongly related to the crack depth, which significantly affects the beam behavior, especially when the crack is very deep where the ANN allows us to identify the crack in lower computational time. Based on the provided results, we can detect that the effect of hidden layer size can affect the results.
\end{abstract}

KEYWORDS. Notched steel beam; Finite element method; Dynamic analysis; Experimental model analysis; ANN; PSO.

\section{open $\bigcirc$ Access}

Citation: Meriem, S., Djamel, N., Djilali, B., Khatir, S., Abdel Wahab, M., N., Crack prediction in beam-like structure using ANN based on frequency analysis, Frattura ed Integrità Strutturale, 59 (2022) 18-34.

Received: 19.08 .2021

Accepted: 05.10.2021

Published: 01.01.2022

Copyright: (C) 2022 This is an open access article under the terms of the CC-BY 4.0, which permits unrestricted use, distribution, and reproduction in any medium, provided the original author and source are credited. 


\section{INTRODUCTION}

B eams have been of great significance in many areas of engineering applications and have generally been used in modeling civil and mechanical engineering problems. In fact, different models and methods have been developed to determine the real response of the beam [1]. However, extensive research on cracked beam behavior based on other improved methods has been done. Yang et al [2] used the energy method to identify the crack in vibrating beams where Galerkin's method has been applied to obtain the vibration modes. The Timoshenko and Euler formulation have been also used to identify the cracks in beam [3] and another approach has been developed for the same concept [4]. Gillich et al $[5,6]$ and Zhou et al. [7,8] examined and detected the damage crack with vibration measurement. The forced vibration of the cracked beam has been also studied [9]. Many other approaches have been used to identify the crack's structures (beam) as the genetic algorithm [10], the efficient hybrid TLBO-PSO-ANN combined to the IGA [11] and the machine learning method $[12,13,14]$. In fact, recently, the concept of machine learning has been applied for damage detection in different structures where the vectorized data has been used by Tran-Ngoc et al [14].

Moreover, an accurate method based on different approaches has also been proposed by different authors to detect the effect of the cracks on the behavior of a beam-like structure, bridges $[15,16,17,18]$ and composite beams $[19,20]$. Khatir et al $[21,22]$ proposed a new method considering the XFEM, XIGA and Jaya algorithm in order to identify the crack in the plate. An improved technique (ANN) combined with the Jaya algorithm has been used where an experimental analysis has been done [22].

The sensitivity of the pipe's damage crack has also been studied. In fact, Li et al [23] added a virtual massed to predict the crack's damage. Lee et al [24] used the energy method and committee of neural networks to identify the crack in the pipe and Seguini et al $[25,26]$ developed a finite element model of cracked and uncracked pipe by using Ansys software, where different crack depths have been created in the middle, in the right and the left of the pipe. Experimental analysis has also been done, and the Neural artificial method has been used to identify the crack of different depths. In fact, the obtained results proved the efficiency of the developed model and the used method.

This paper investigates by means of numerical and experimental analysis the frequencies and how these later vary depending on the crack depth. However, the results of the study prove the efficiency of the improved machine learning method ANNPSO which allows us to obtain more accurate results where this later is described in details by Seguini et al $[25,26]$. The obtained results from the experimental method were compared with an exact numerical method to check the accuracy of the solutions where the frequencies for each depth crack are obtained. Good agreements were found. In fact, a small difference between the numerical and experimental results was also found. A numerical example of the beams with single and double cracks based on the finite element method has been performed, and conclusions based on these results are derived.

\section{NUMERICAL ANALYSIS}

$\mathrm{T}$ he finite element method is one of the most generally used techniques. In order to study and analyze the behavior of the cracked and uncracked 3D steel beams (Fig. 1, 2), the Ansys software (v18.1) has been used. However, two examples of a beam with different properties have been analyzed. The mechanical characteristics of beam I and beam II are respectively presented in Tab. 1 and Tab. 2. Moreover, for each depth crack, the frequencies of different mode shapes have been determined and resumed in the following tables.

\section{Example 1}

In the first example of a beam, double notches have been created in the middle of this later with 25 depths (Fig. 3). The cracks are extended from $1 \mathrm{~mm}$ to $25 \mathrm{~mm}$. In fact, a depth crack of $1 \mathrm{~mm}$ has been created at the top and the bottom, as shown in Fig. 3. Some mode shapes are presented in Figs. 4,5,6, and 7. The frequencies for the healthy and double notched beam from the numerical and experimental analysis is presented in Tab. 3, 4 and all the numerical ones are resumed in Tab. 5.

From the obtained results, it can be concluded that there is a decrease in frequencies with the increase of the crack depth (Tab. 5), and the percentage of error between experimental and numerical results is very small see Tab. 3, 4. 


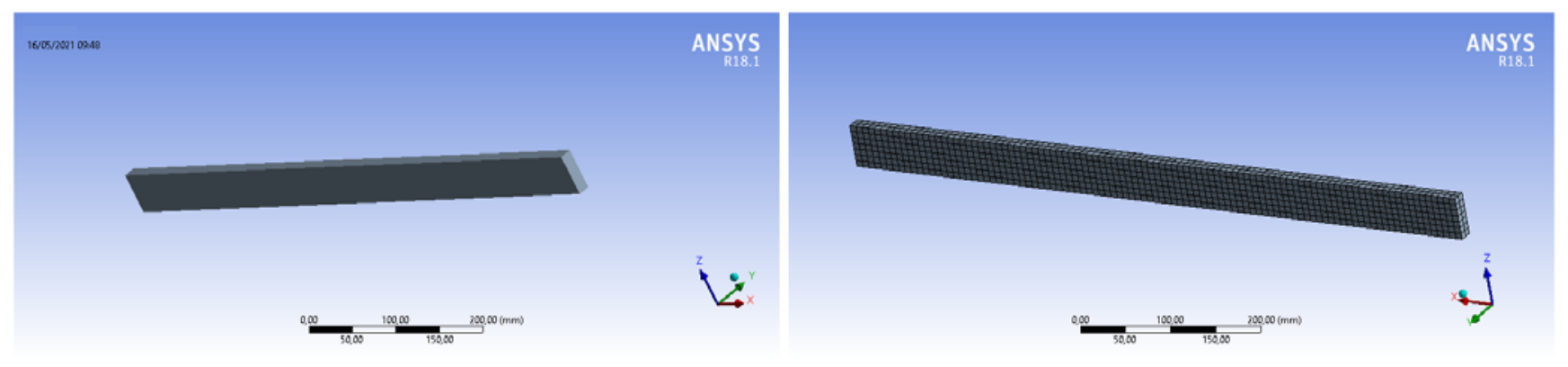

Figure 1: Finite element model of beam I.
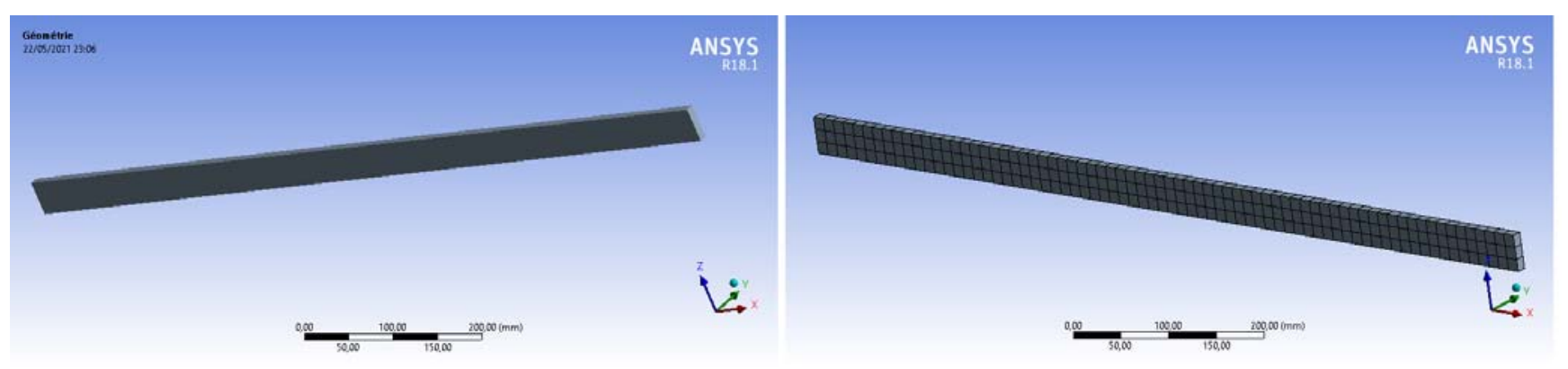

Figure 2: Finite element model of beam II.

\begin{tabular}{ccc}
\hline Item & Notation & Value \\
Length $(\mathrm{mm})$ & $\mathrm{L}_{1}$ & 800 \\
Width $(\mathrm{mm})$ & $\mathrm{b}_{1}$ & 15 \\
Hight $(\mathrm{mm})$ & $\mathrm{h}_{1}$ & 50 \\
Density $\left(\mathrm{kg} / \mathrm{m}^{3}\right)$ & $\varrho$ & 7850 \\
Poisson ratio $(/)$ & $\nu$ & 0.3 \\
Young modulus $(\mathrm{GPa})$ & $\mathrm{E}$ & $2.1 \times 10^{11}$ \\
\hline
\end{tabular}

Table 1: Dimensions and material characteristics of beam I.

\begin{tabular}{ccc}
\hline Item & Notation & Value \\
Length $(\mathrm{mm})$ & $\mathrm{L}_{1}$ & 1000 \\
Width $(\mathrm{mm})$ & $\mathrm{b}_{1}$ & 10 \\
Hight $(\mathrm{mm})$ & $\mathrm{h}_{1}$ & 40 \\
Density $\left(\mathrm{kg} / \mathrm{m}^{3}\right)$ & $\varrho$ & 7850 \\
Poisson ratio $(/)$ & $\nu$ & 0.3 \\
Young modulus $(\mathrm{GPa})$ & $\mathrm{E}$ & $2.1 \times 10^{11}$ \\
\hline
\end{tabular}

Table 2: Dimensions and material characteristics of beam II. 
(a)

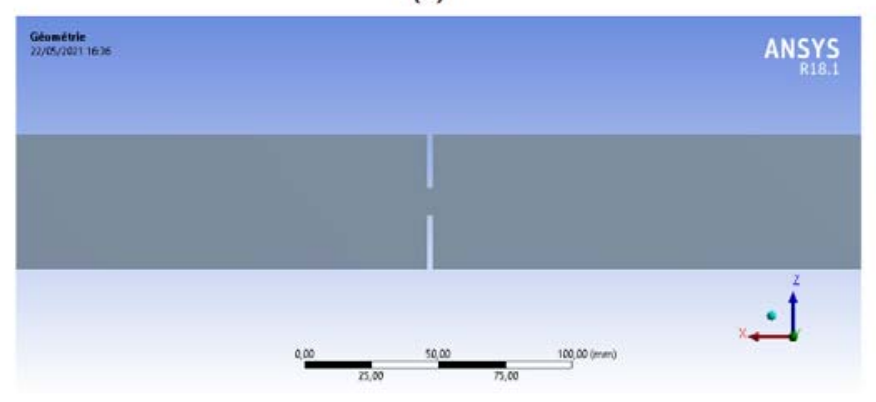

(c)

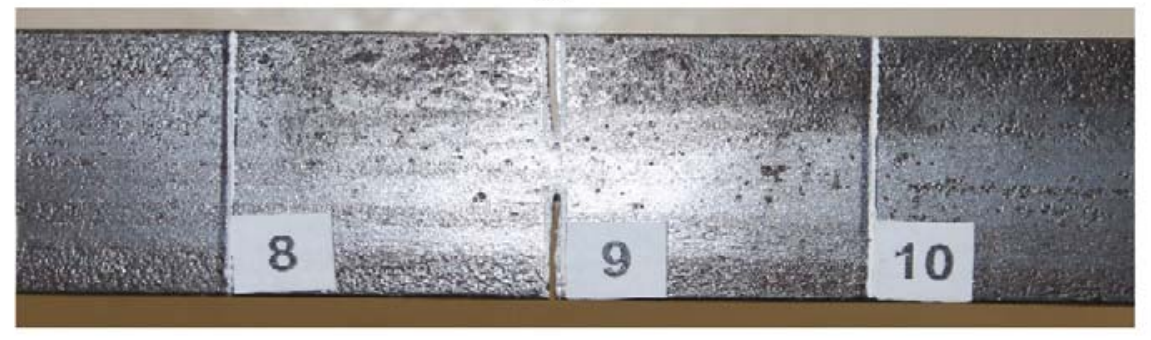

Figure 3: cracked beam I: (a) Finite element model; (b) meshed beam; (c) experimental model.

(b)

(c)

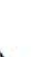

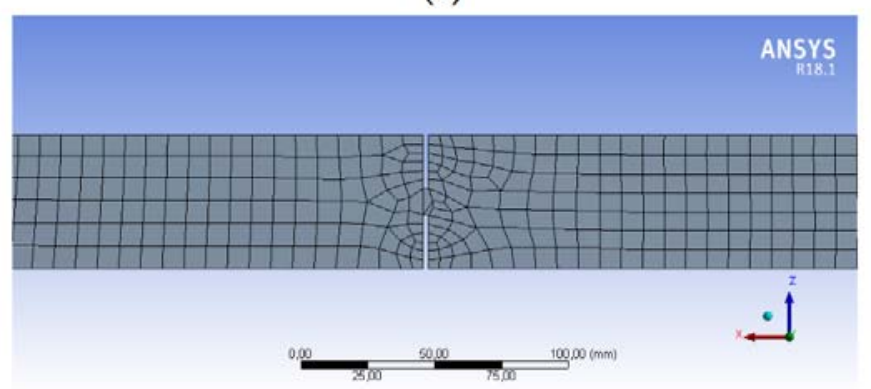


(a)

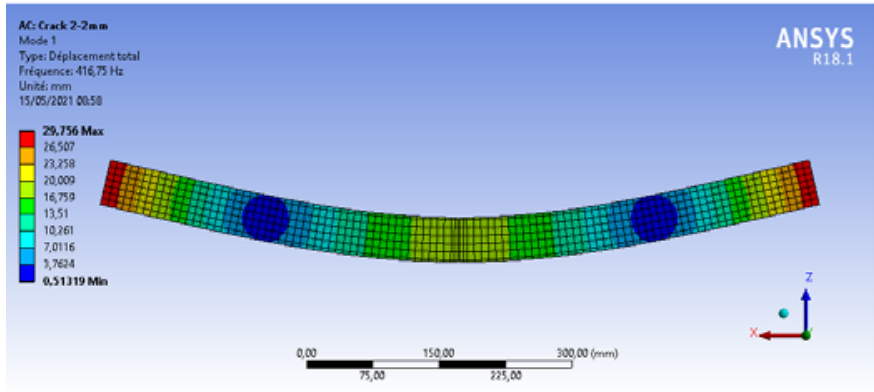

(b)

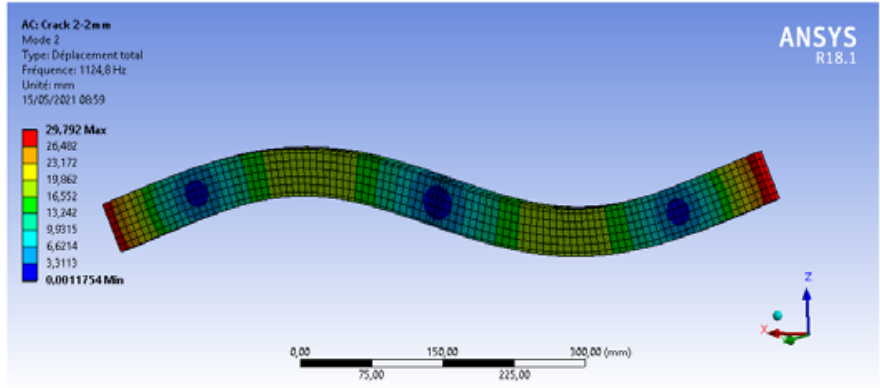

(c)

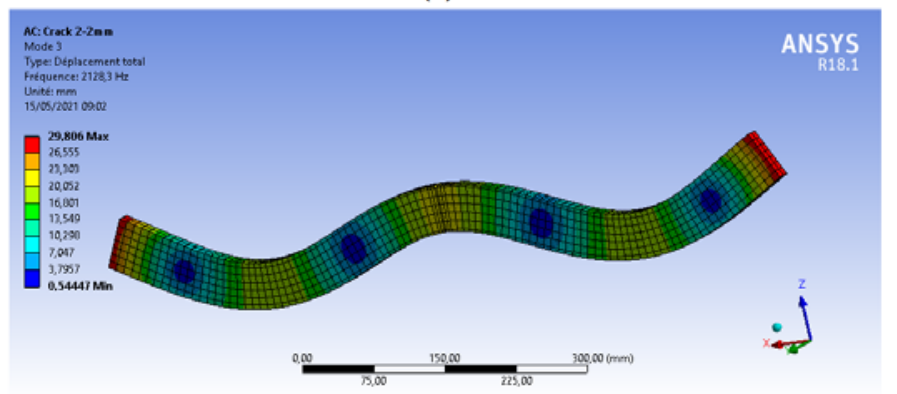

Figure 5: Natural frequencies of a double notched beam with 2-2 mm of depth (double notched): (a) mode 1; (b) mode2 ; (c) mode 3.

(a)

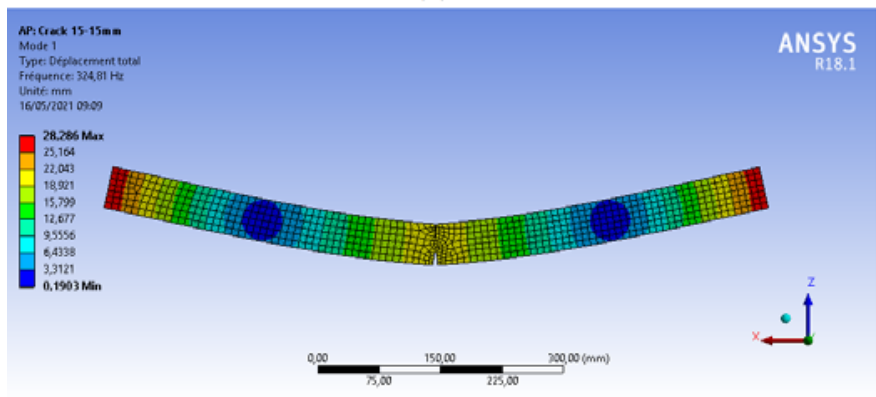

(b)

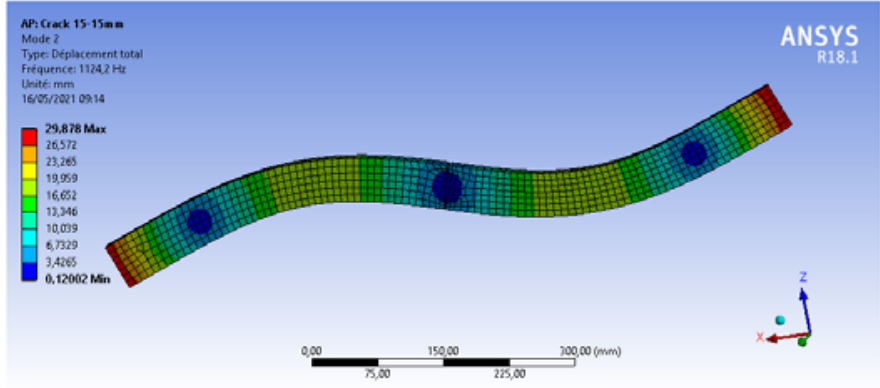

(c)

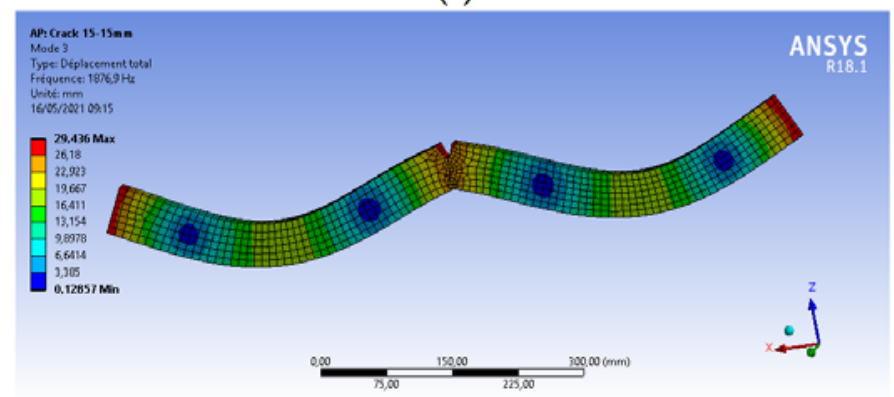

Figure 6: Natural frequencies of a double notched beam with 15-15 mm of depth (double notched): (a) mode 1; (b) mode2 ; (c) mode 3. 
(a)

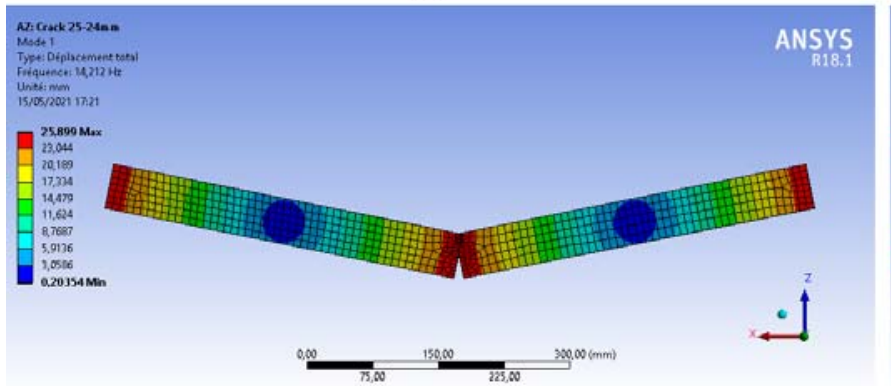

(b)

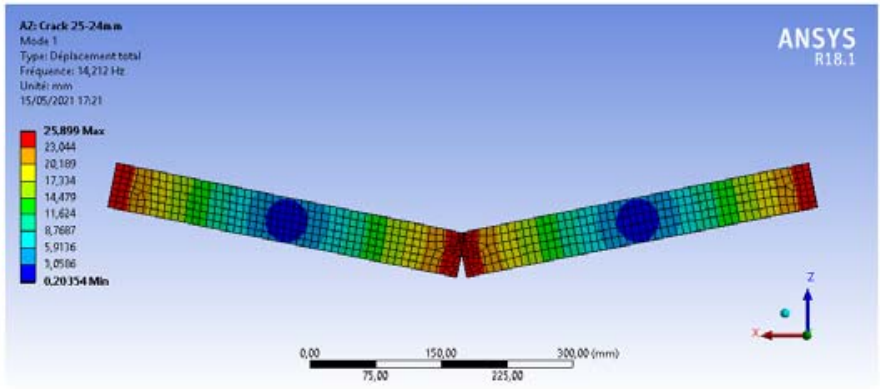

(c)

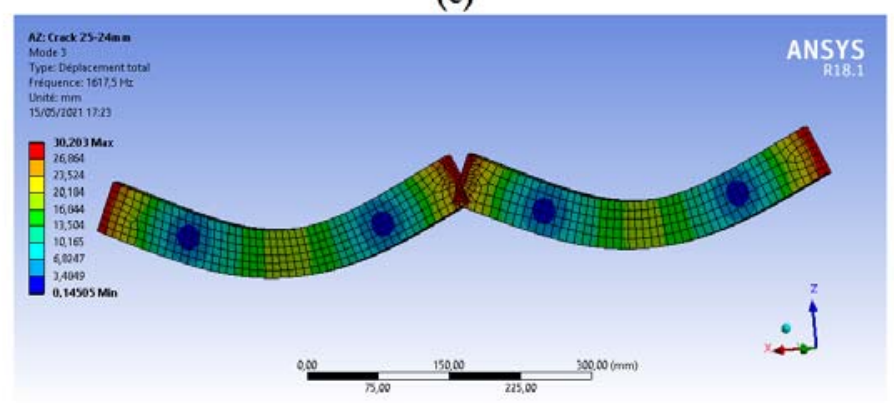

Figure 7: Natural frequencies of a double notched beam with 24-25 mm of depth (double notched): (a) mode 1; (b) mode 2; (c) mode 3.

\begin{tabular}{cccc}
\hline Mode & FEM & Experimental & Error $(\%)$ \\
1 & 418.63 & 418.75 & 0.00029 \\
2 & 1126.2 & 1126.3 & 0.00008 \\
3 & 2135.8 & 2134 & 0.00084 \\
\hline
\end{tabular}

Table 3: The measured frequencies of uncracked beam I.

\begin{tabular}{cccc}
\hline Mode & FEM & Experimental & Error $(\%)$ \\
1 & 413.23 & 412.81 & 0.0010 \\
2 & 1124.8 & 1125.3 & 0.00044 \\
3 & 2115.8 & 2111.13 & 0.0022 \\
\hline
\end{tabular}

Table 4: The measured frequencies of a double notched beam (4-4 mm).

\section{Example 2}

In the second example (beam II), 20 crack depths have been created in the middle by extending the crack from $2 \mathrm{~mm}$ to 32 $\mathrm{mm}$ with $1 \mathrm{~mm}$ step. The obtained frequencies of each mode shape have been resumed in Tab. 6,7 and compared to the experimental results, and all the numerical ones are presented in Tab. 8.

From the obtained results, it can be deduced that the frequencies decrease with the increase of the crack depth (Tab. 8), and the percentage of error between experimental and numerical results is also very small see Tabs. 6, 7. 


\begin{tabular}{|c|c|c|c|}
\hline Crack depth & Mode 1 & Mode 2 & Mode 3 \\
\hline $1-1(\mathrm{~mm})$ & 417.85 & 1124.8 & 2132.3 \\
\hline $2-2(\mathrm{~mm})$ & 416.75 & 1124.8 & 2128.3 \\
\hline 3-3 (mm) & 415.24 & 1124.8 & 2122.9 \\
\hline 4-4 (mm) & 413.23 & 1124.8 & 2115.8 \\
\hline 5-5 (mm) & 410.65 & 1124.8 & 2106.8 \\
\hline 6-6 (mm) & 407.4 & 1124.8 & 2095 \\
\hline 7-7 (mm) & 403.07 & 1124.8 & 2079 \\
\hline $8-8(\mathrm{~mm})$ & 398.35 & 1124.8 & 2060.7 \\
\hline $9-9(\mathrm{~mm})$ & 391.36 & 1124.7 & 2043.8 \\
\hline $10-10(\mathrm{~mm})$ & 388.41 & 1124.7 & 2032.9 \\
\hline $11-11(\mathrm{~mm})$ & 375.78 & 1124.6 & 1998.2 \\
\hline $12-12(\mathrm{~mm})$ & 371.97 & 1124.5 & 1971.8 \\
\hline 13-13 (mm) & 354.35 & 1124.5 & 1942.5 \\
\hline 14-14 (mm) & 349.33 & 1124.3 & 1931.1 \\
\hline $15-15(\mathrm{~mm})$ & 326.81 & 1124.2 & 1876.9 \\
\hline $16-16(\mathrm{~mm})$ & 324.9 & 1124 & 1872.8 \\
\hline $17-17(\mathrm{~mm})$ & 295.3 & 1123.9 & 1822.3 \\
\hline 18-18 (mm) & 283.76 & 1123.8 & 1803.6 \\
\hline $19-19(\mathrm{~mm})$ & 240.05 & 1123.1 & 1741.9 \\
\hline $20-20(\mathrm{~mm})$ & 235.48 & 1123 & 1739 \\
\hline $21-21(\mathrm{~mm})$ & 161.64 & 1122.7 & 1672.2 \\
\hline $22-22(\mathrm{~mm})$ & 121.48 & 1121.1 & 1646.4 \\
\hline 23-23 (mm) & 84.51 & 1119.6 & 1631.1 \\
\hline 24-24 (mm) & 36.516 & 1114.6 & 1619.8 \\
\hline $25-25(\mathrm{~mm})$ & 14.212 & 1098.6 & 1617.5 \\
\hline
\end{tabular}

Table 5: Numerical frequencies of different crack depth (beam I).

(a)

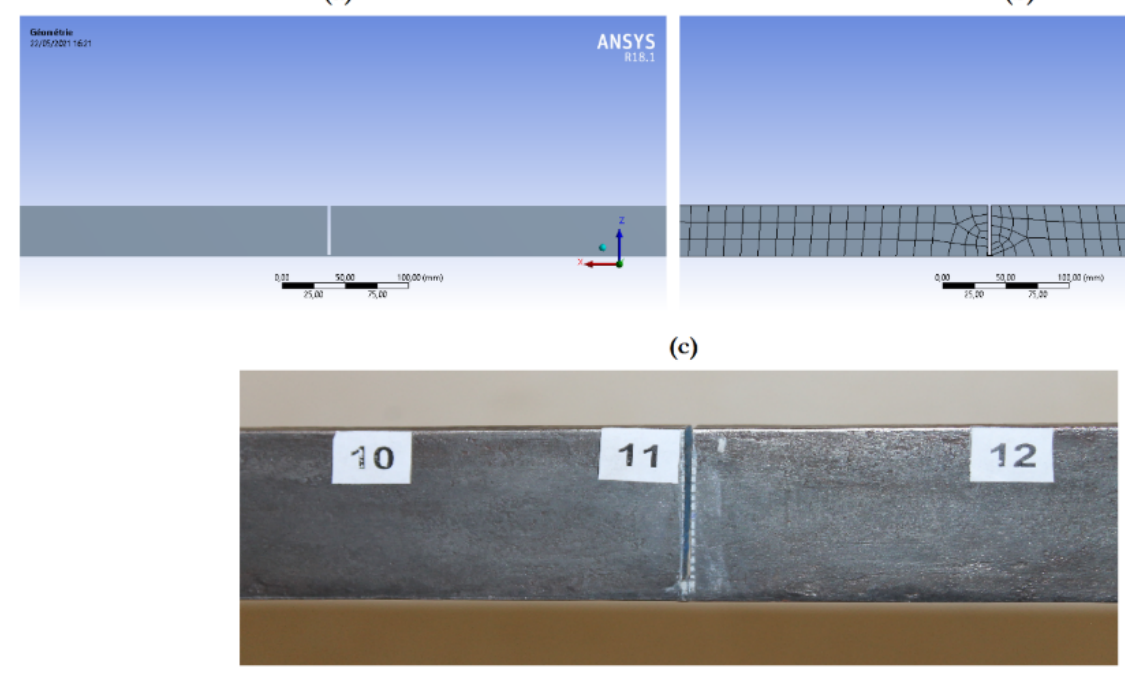

Figure 8: Cracked beam II: (a) Finite element model; (b) meshed beam; (c) experimental model. 


\begin{tabular}{cccc}
\hline Mode & FEM & Experimental & Error $(\%)$ \\
1 & 212.13 & 211.33 & 0.0038 \\
2 & 578.7 & 578.52 & 0.00031 \\
3 & 1117.9 & 1121.7 & 0.0033 \\
4 & 1813.4 & 1821.1 & 0.0042 \\
\hline
\end{tabular}

Table 6: Measured frequencies of uncracked beam II.

\begin{tabular}{cccc}
\hline Mode & FEM & Experimental & Error $(\%)$ \\
1 & 210.66 & 209.53 & 0.0054 \\
2 & 578.69 & 577.50 & 0.0020 \\
3 & 1112 & 1114.4 & 0.0021 \\
4 & 1812.7 & 1817.7 & 0.0027 \\
\hline
\end{tabular}

Table 7: Measured frequencies of cracked beam II (4 mm).

(a)

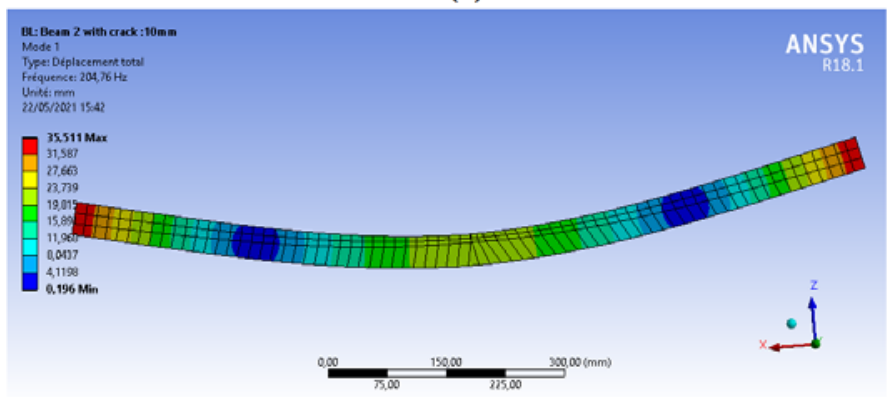

(c)

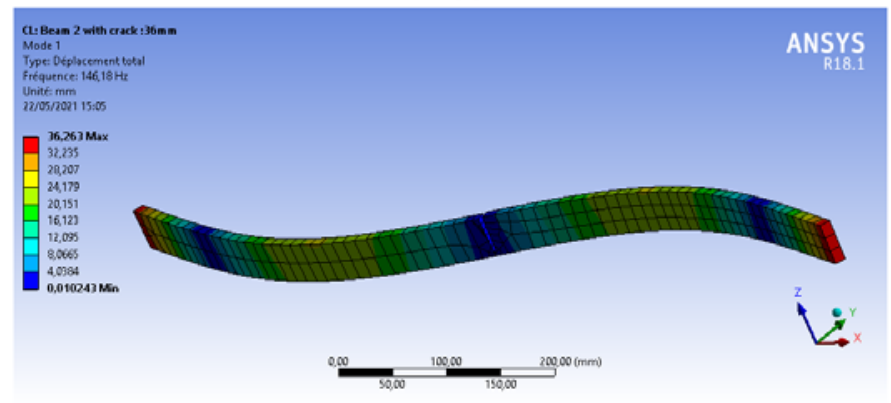

(b)

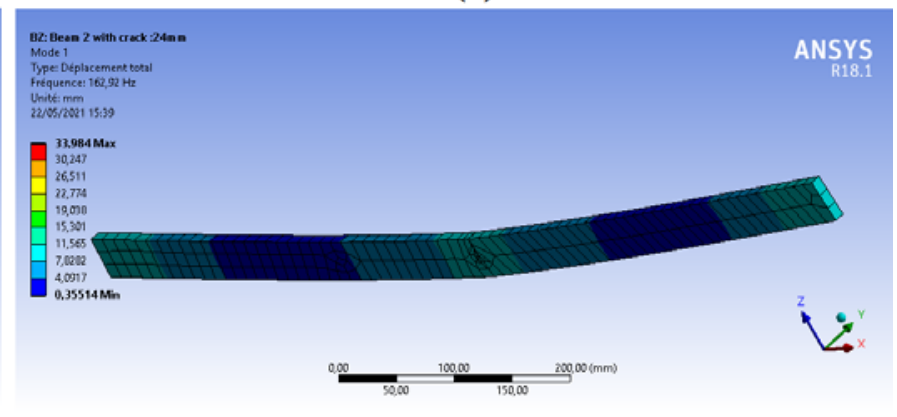

(d)

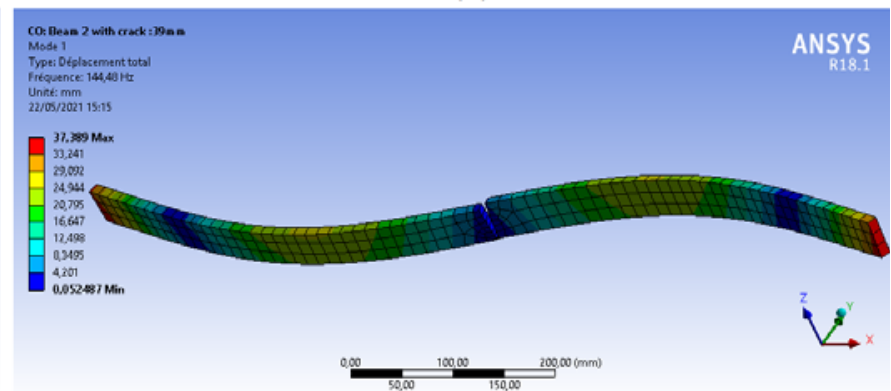

Figure 9: Natural frequencies (mode 1): (a) Cracked beam with 10mm of depth; (b) Cracked beam with $24 \mathrm{~mm}$ of depth; (c) Cracked beam with $36 \mathrm{~mm}$ of depth and (d) Cracked beam with $39 \mathrm{~mm}$ of depth. 
(a)

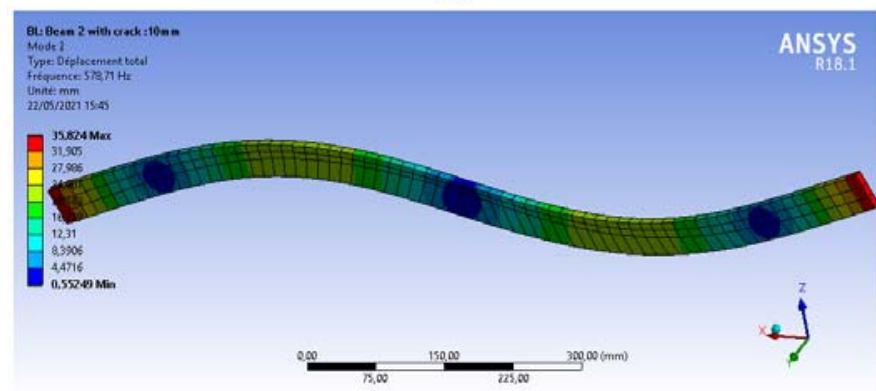

(c)

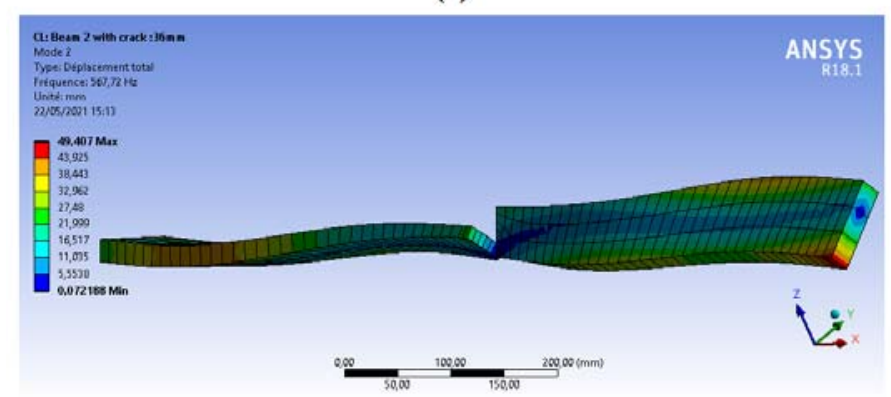

(b)

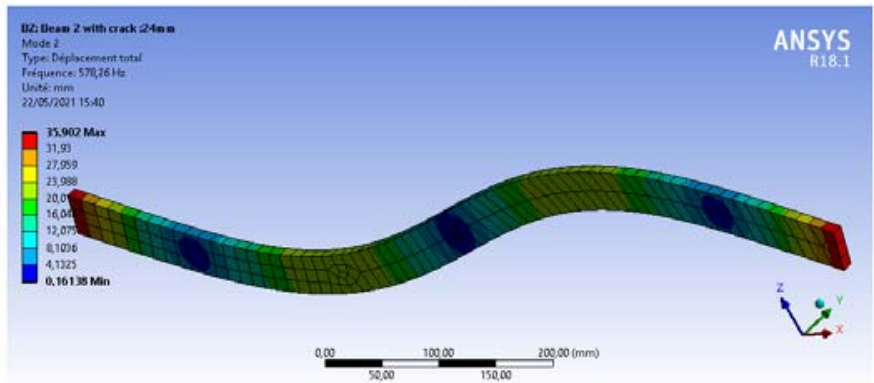

(d)

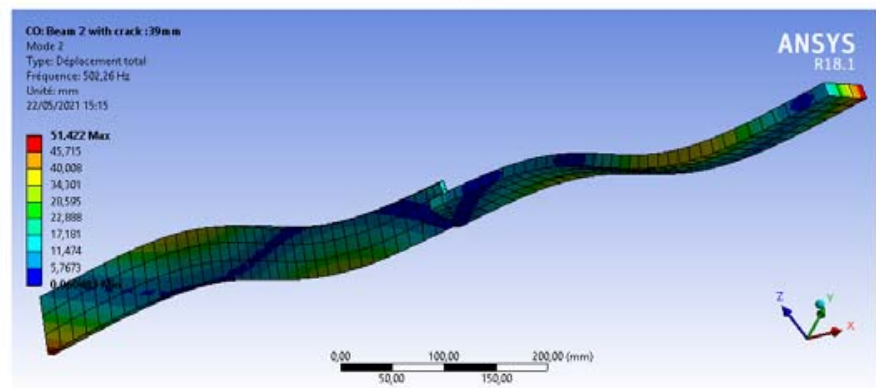

Figure 10: Natural frequencies (mode 2): (a) Cracked beam with 10mm of depth; (b) Cracked beam with 24 mm of depth; (c) Cracked beam with $36 \mathrm{~mm}$ of depth and (d) Cracked beam with $39 \mathrm{~mm}$ of depth.

(a)

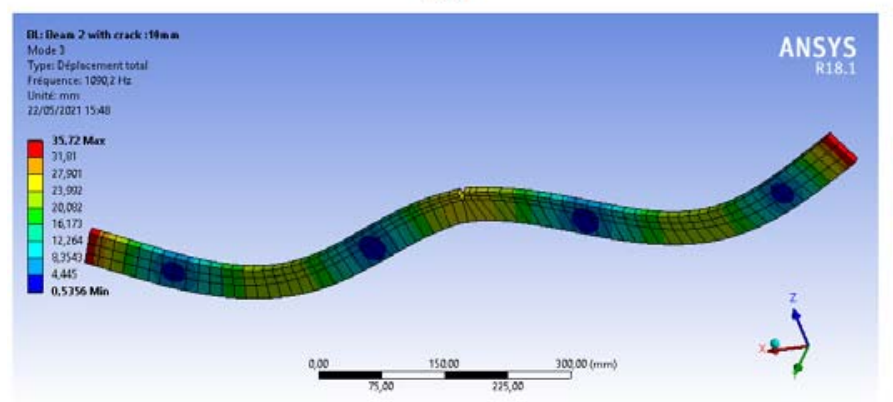

(c)

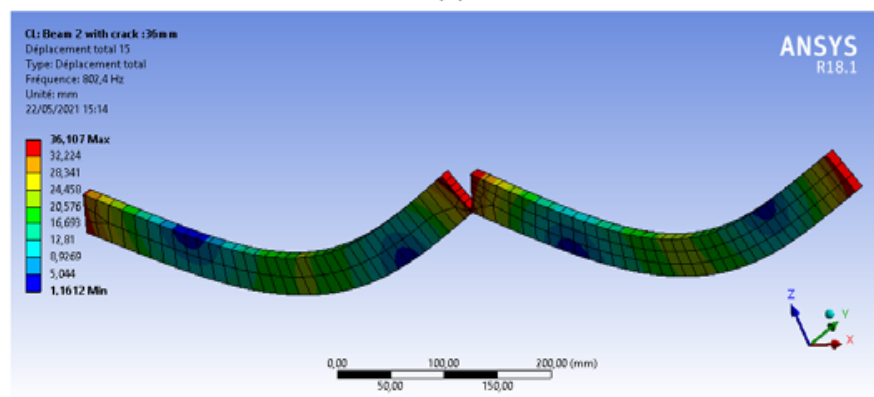

(b)

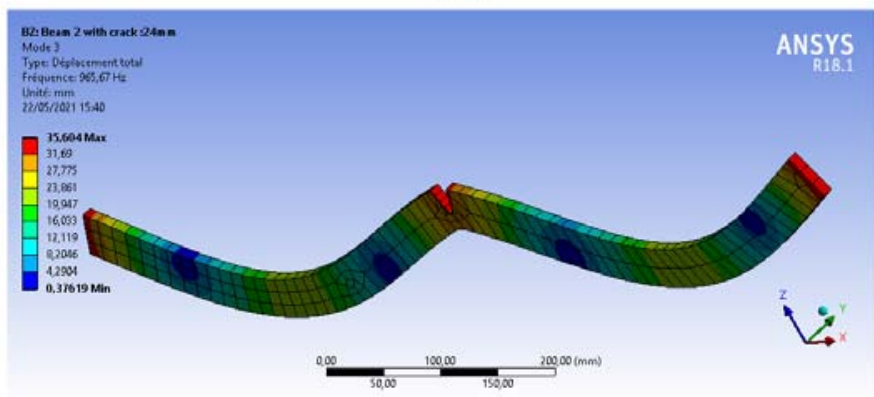

(d)

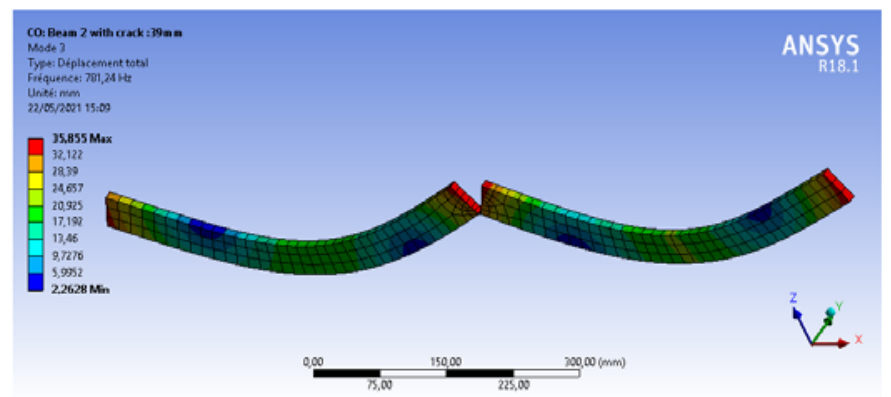

Figure 11: Natural frequencies (mode 3): (a) Cracked beam with 10mm of depth; (b) Cracked beam with 24 mm of depth; (c) Cracked beam with $36 \mathrm{~mm}$ of depth and (d) Cracked beam with $39 \mathrm{~mm}$ of depth. 


\begin{tabular}{|c|c|c|c|}
\hline Crack depth (mm) & Mode 1 & Mode 2 & Mode 3 \\
\hline 1 & 212.03 & 578.68 & 1117.4 \\
\hline 2 & 211.78 & 578.68 & 1116.4 \\
\hline 3 & 211.21 & 578.58 & 1114.1 \\
\hline 4 & 210.66 & 578.69 & 1112 \\
\hline 5 & 209.92 & 578.69 & 1109.4 \\
\hline 6 & 209.14 & 578.69 & 1106.4 \\
\hline 7 & 208.23 & 578.68 & 1103.0 \\
\hline 8 & 207.19 & 578.73 & 1099.2 \\
\hline 9 & 206.03 & 578.72 & 1094.9 \\
\hline 10 & 204.76 & 578.71 & 1090.2 \\
\hline 11 & 204.37 & 578.69 & 1088.7 \\
\hline 12 & 202.15 & 578.68 & 1080.7 \\
\hline 13 & 200.48 & 578.66 & 1074.8 \\
\hline 14 & 198.57 & 578.65 & 1068.2 \\
\hline 15 & 195.68 & 578.62 & 1058.5 \\
\hline 16 & 194.04 & 578.61 & 1053.1 \\
\hline 17 & 190.61 & 578.57 & 1042.1 \\
\hline 18 & 188.3 & 578.55 & 1034.9 \\
\hline 19 & 185.48 & 578.51 & 1026.4 \\
\hline 20 & 181.51 & 578.48 & 1014.7 \\
\hline 21 & 177.39 & 578.43 & 1003 \\
\hline 22 & 172.96 & 578.39 & 991.02 \\
\hline 23 & 170.16 & 578.36 & 983.69 \\
\hline 24 & 162.92 & 578.26 & 965.67 \\
\hline 25 & 157.5 & 578.19 & 952.94 \\
\hline 26 & 150.97 & 578.18 & 938.45 \\
\hline 27 & 146.81 & 578.07 & 924.08 \\
\hline 28 & 146.79 & 578 & 911.8 \\
\hline 29 & 146.76 & 577.87 & 896.31 \\
\hline 30 & 146.74 & 577.83 & 886.75 \\
\hline 31 & 146.74 & 577.78 & 882.01 \\
\hline 32 & 146.67 & 577.55 & 856.86 \\
\hline 33 & 146.61 & 577.36 & 838.72 \\
\hline 34 & 146.5 & 576.95 & 832.61 \\
\hline 35 & 146.38 & 576.71 & 812.76 \\
\hline 36 & 146.18 & 567.72 & 802.4 \\
\hline 37 & 145.85 & 538.03 & 794.3 \\
\hline 38 & 144.97 & 506.77 & 785.45 \\
\hline 39 & 144.48 & 502.26 & 781.24 \\
\hline
\end{tabular}

Table 8: Experimental frequencies of different crack depths (beam II).

\section{EXPERIMENTAL ANALYSIS}

$\mathrm{I}$ $\mathrm{n}$ this section, the healthy and damaged free-free beams have been analyzed by using M+P SO Analyzer 4.3, PCB Accelerometers 356A15, and Hammer PCB 086C03. In the first example, the accelerometer has been put on the left side of the beam (Fig. 12c) to determine the frequencies where 19 excisions have been generated by a Hammer, and ten double notches have been created in the middle of the beam I. On the other hand, in the second beam, the accelerometer is located in the right of this later where five crack depths have created in the middle of the beam, and the frequencies of 3 mode shapes have been calculated after the average of 11 positions of hammer impact. 
(a)

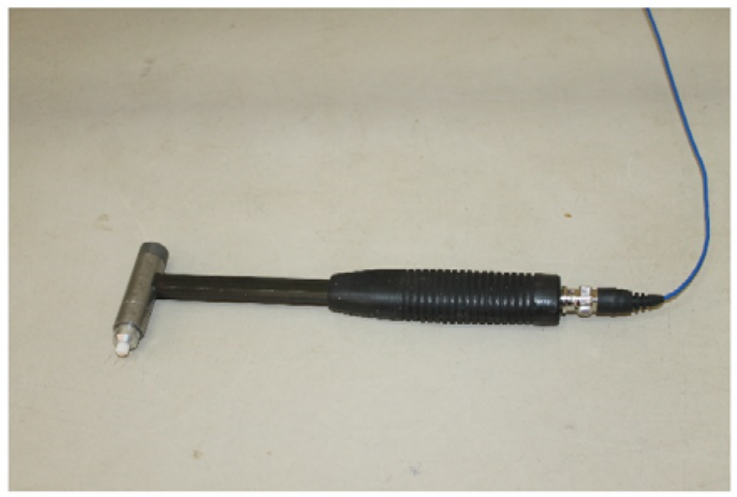

(b)

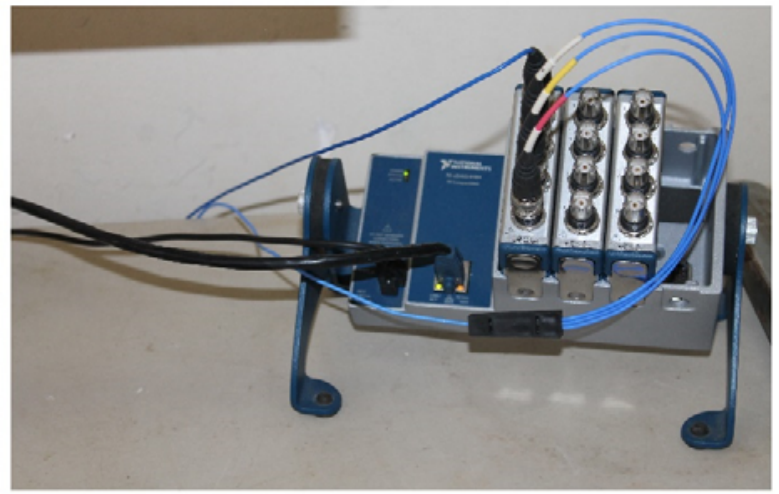

(c)

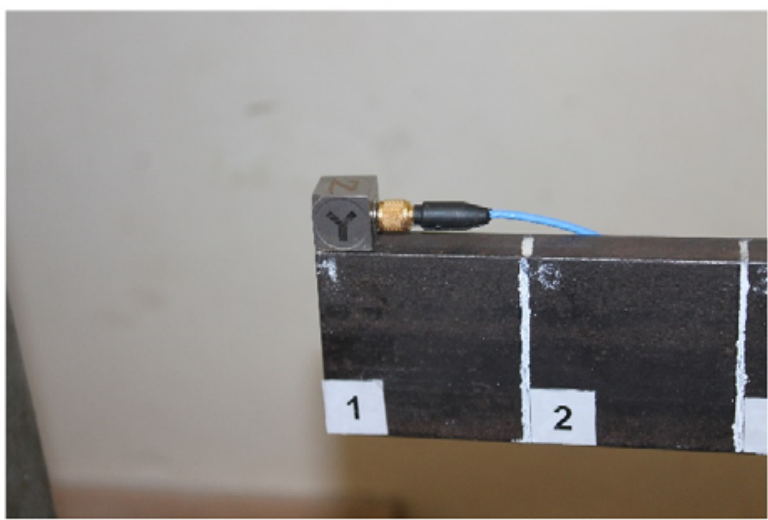

Figure 12: (a) Hammer PCB 086C03; (b) Analyzer 4.3; and (c) Accelerometers 356A15.

\section{Example 1}

In the first example of a beam, a double crack has been created in the middle, as shown in Fig. 13 middle, by extending the crack from $2 \mathrm{~mm}$ to $20 \mathrm{~mm}$ with $2 \mathrm{~mm}$ step on the top and bottom and the obtained frequencies of 3 mode shape have been resumed in Tab. 9.

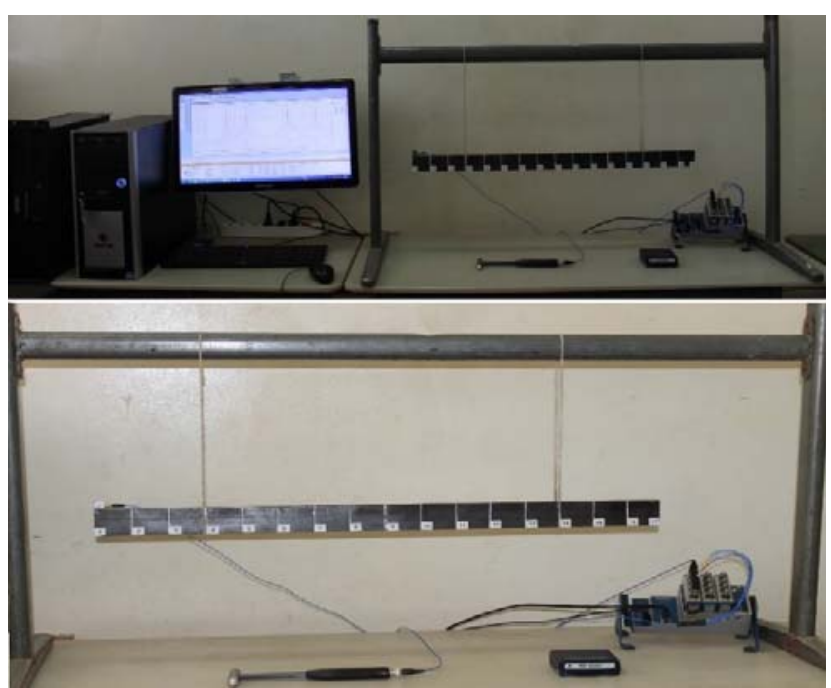

Figure 13: Setup modal analysis of cracked beam I. 


\begin{tabular}{cccc}
\hline Crack depth & Mode 1 & Mode 2 & Mode 3 \\
\hline $2-2(\mathrm{~mm})$ & 417.19 & 1125.3 & 2126.3 \\
$4-4(\mathrm{~mm})$ & 412.81 & 1125.3 & 2111.13 \\
$6-6(\mathrm{~mm})$ & 407.50 & 1125.3 & 2091.6 \\
$8-8(\mathrm{~mm})$ & 398.44 & 1124.7 & 2058 \\
$10-10(\mathrm{~mm})$ & 388.13 & 1124.4 & 2037.2 \\
$12-12(\mathrm{~mm})$ & 372.19 & 1124.4 & 1990.6 \\
$14-14(\mathrm{~mm})$ & 349.69 & 1124.4 & 1930 \\
$16-16(\mathrm{~mm})$ & 325.63 & 1124.4 & 1872.5 \\
$18-18(\mathrm{~mm})$ & 285.31 & 1124.1 & 1801.6 \\
$20-20(\mathrm{~mm})$ & 236.56 & 1124.1 & 1740.6 \\
\hline
\end{tabular}

Table 9: Experimental frequencies of different crack depth (beam I).

\section{Example 2}

In the second example of a beam, a double crack has been created in the middle as shown in Fig. 14 middle, by extending the crack from $2 \mathrm{~mm}$ to $10 \mathrm{~mm}$ with $2 \mathrm{~mm}$ step and the obtained frequencies of 4 mode shape have been resumed in Tab. 9.
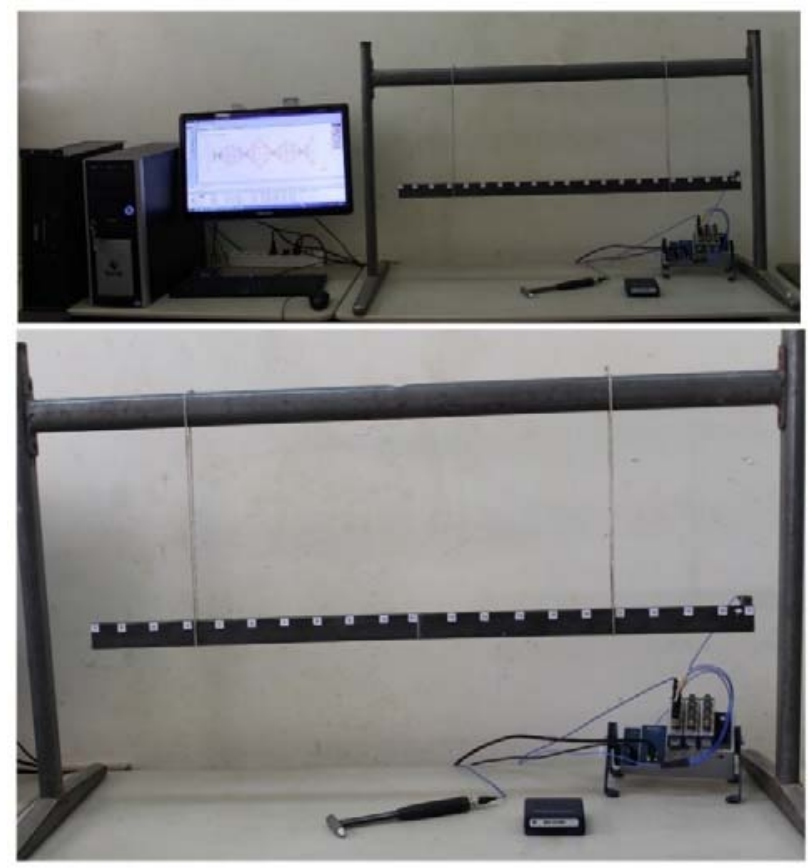

Figure 14: Setup modal analysis of cracked beam II.

\begin{tabular}{cccc}
\hline Crack depth $(\mathrm{mm})$ & Mode 1 & Mode 2 & Mode 3 \\
2 & 210.63 & 577.34 & 1118.3 \\
4 & 209.53 & 577.50 & 1114.4 \\
6 & 208.13 & 577.03 & 1107.8 \\
8 & 205.31 & 576.72 & 1095.9 \\
10 & 202.81 & 577.34 & 1086 \\
\hline
\end{tabular}

Table 10: Experimental frequencies of different crack depths (beam II). 


\section{ARTIFICIAL NEURAL NETWORK FOR CRACK PREDICTION}

$\mathrm{I}$ $\mathrm{n}$ this section, ANN technique is used for crack prediction based on previous beams. The Artificial Neural Network (ANN) is a computational technique based on biological nervous systems. The ability to learn from experience in order to enhance results is the most important aspect of ANN. As a consequence, ANN can be used in a number of applications, including classification, control systems, detection, image processing, and pattern recognition. As shown in Fig 15, an ANN consists of three major components: an input layer, a hidden layer, and an output layer.

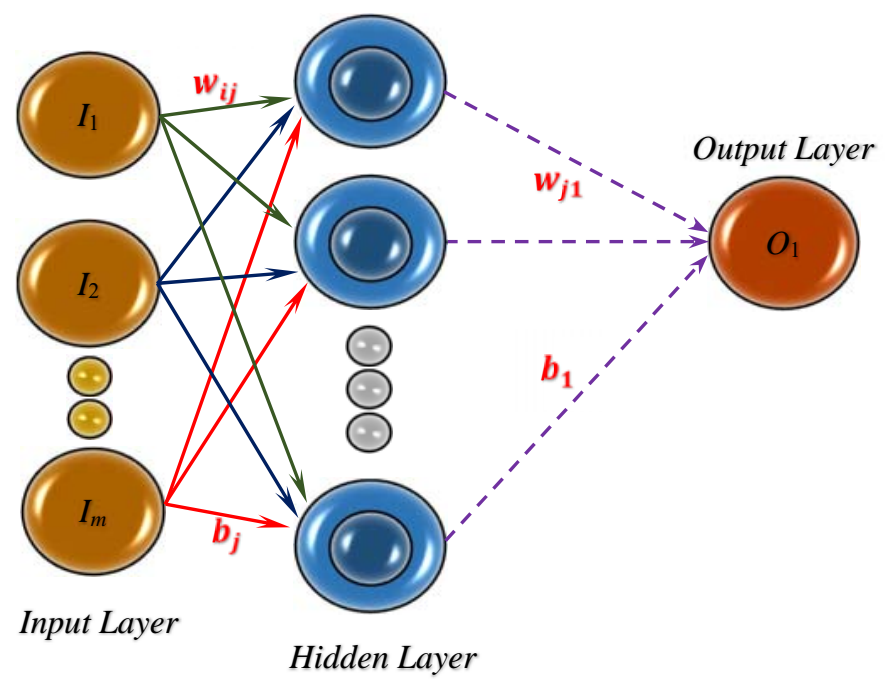

Figure 15: ANN architecture.

where $w_{i j}$ is the weights of neuron connection between an input node and neuron in the hidden layers, bj is the bias, $w_{j 1}$ is the weight of neuron connection between neuron in hidden and output layers. $b_{1}$ is the bias associated with the single neuron in the output layer. Index $\mathrm{i}=1,2, \ldots, m$ is the number of collected data and index $j=1,2, \ldots, \mathrm{n}$ is the number of hidden layer neurons. The total number of parameters (weight and bias) used in the network is $n \times(m+2)+1$.

Two formulations are used to move from the input to the output layer during the process. First, a summation function related to training parameters and output of previous layers is presented in the following formulation:

$$
\Phi_{j}=\Phi\left(\sum_{i=1}^{n} w_{i j} f_{i}+b_{j}\right), j=(1-m)
$$

where $w$ and $b$ denote weight and bias represent training parameters, $n$ presents the number of data textracted into the input layer, and $m$ presents the number of neurons selected in the hidden layer. $\Phi_{j}$ and $f_{i}$ are input and output data, respectively. Next, $\Phi_{j}$ is determined by computing the output of the hidden layer as presented in the following formulation:

$$
\Phi_{j}^{1}=\frac{1}{1+e^{-\Phi_{j}}}
$$

Different Gaussian, Step, Ramp, and Sigmoid functions are used to solve different problems. Our paper uses the Sigmoid function based on the objectives that can solve linear and nonlinear problems. After building the structure of the ANN model, training with known input and the output sets is performed to find the suitable hidden layer size. Six cases are provided to test the effectiveness of hidden layer size. The regression using 8,10, and 12 Hidden layer sizes (HLS) are presented for both beams see Figs 16-17. 


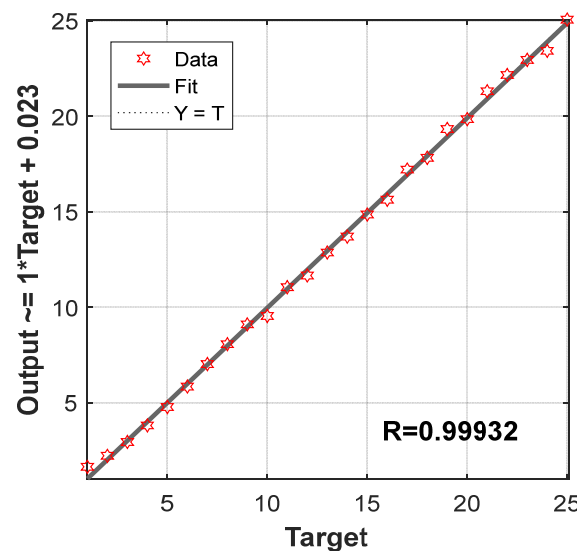

HLS $=8$

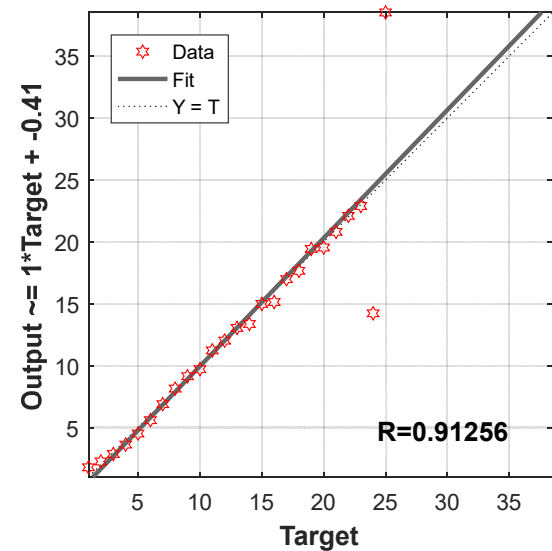

HLS $=10$

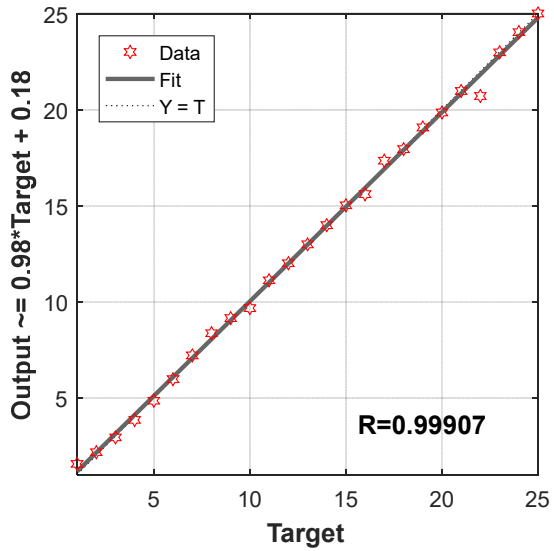

HLS $=12$

Figure 16: Regression with different Hidden layer sizes (HLS). Beam I

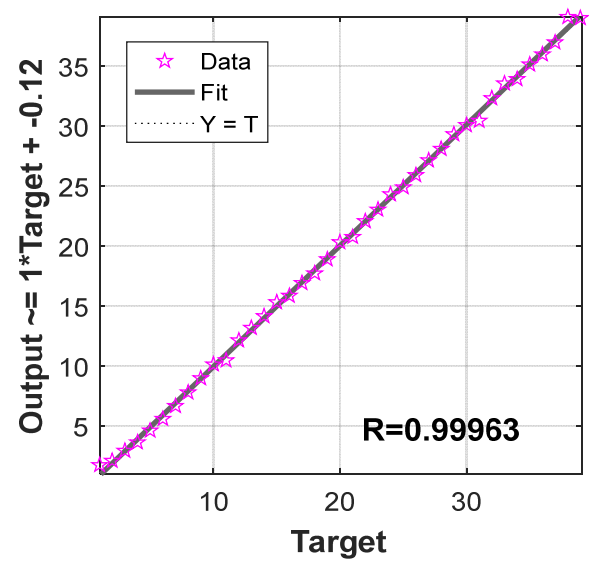

HLS $=8$

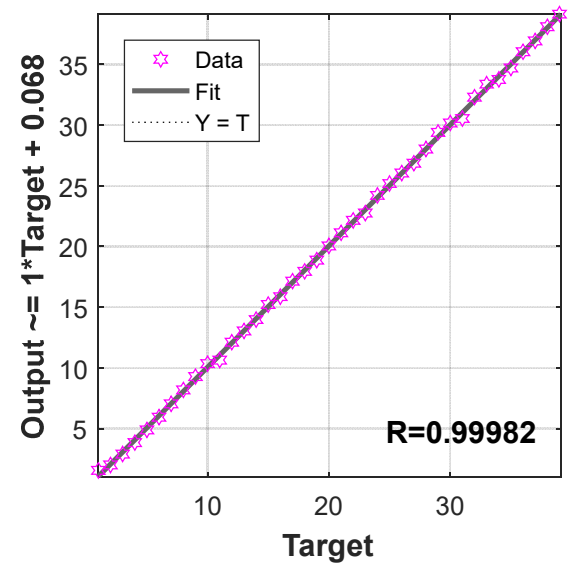

HLS $=10$

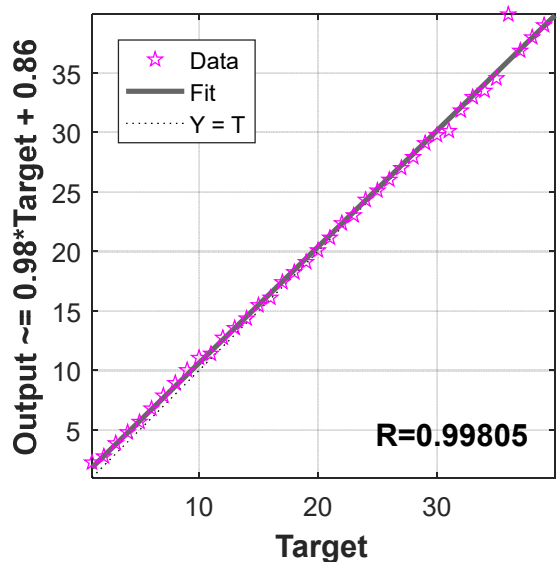

HLS $=12$

Figure 17: Regression with different Hidden layer sizes (HLS). Beam II

Based on the results in Figs. 16-17 the best regression can be found when HLS is 8 for beam I. And 10 for beam II. The estimated results can be summarized in Tab. 11.

\begin{tabular}{|c|c|c|c|c|}
\hline BEAM & $\begin{array}{c}\text { ACTUAL } \\
\text { CRACK } \\
\text { LENGTH }\end{array}$ & NHLS $=8$ & NHLS $=10$ & NHLS $=12$ \\
\hline \multirow{3}{*}{1} & CASE 1: 4-4 & 3.80911 & 3.614833 & 3.84674 \\
\hline & CASE 2: 10-10 & 9.54634 & 9.710795 & 9.66756 \\
\hline & CASE 3: $20-20$ & 19.86071 & 19.53756 & 19.848808 \\
\hline \multirow{3}{*}{2} & CASE 4: 8 & 7.807456 & 8.18362 & 8.93587 \\
\hline & CASE 5: 15 & 15.32850 & 15.22022 & 15.47560 \\
\hline & CASE 6: 25 & 24.90070 & 25.19147 & 25.11821 \\
\hline
\end{tabular}

Table 11: Exact and estimated results using different HLS for a beam I and II. 


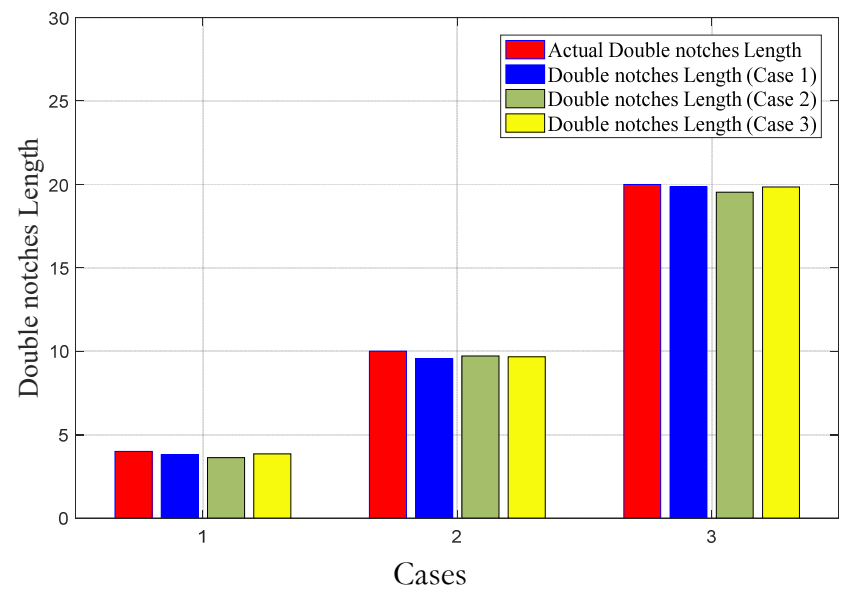

(a)

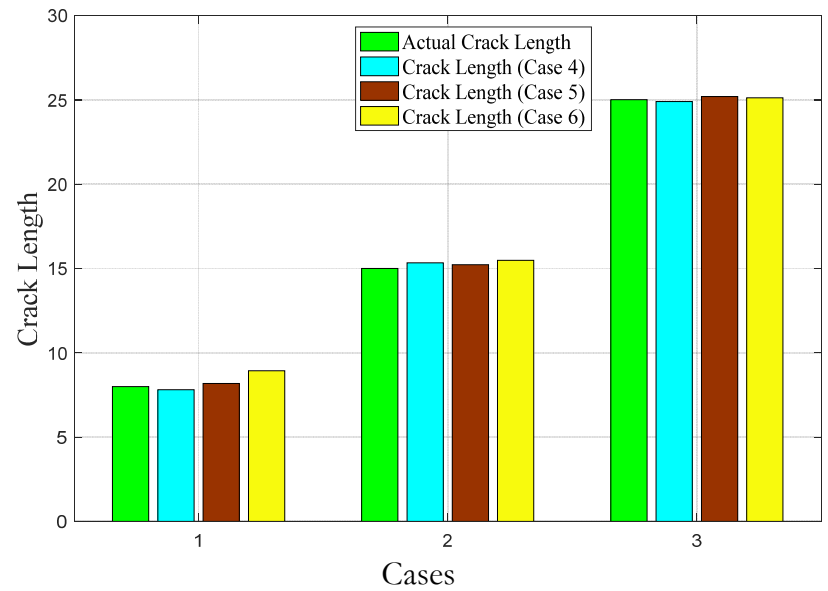

(b)

Figure 18: Actual and predicted double notches length beam I (a) and Crack length beam II (b).

\section{CONCLUSION}

$\mathrm{I}$ $\mathrm{n}$ this study, numerical and experimental modal analysis of two kinds of beam has been done where a new approach has been adopted in order to identify the cracks. In fact, one of the most important contributions of this work is the clear demonstration that the inherent crack depth can have a significant effect on the response of the beam. From this work, the main conclusions are given below:

$\checkmark$ The frequencies varied with the crack depth

$\checkmark$ The experimental and numerical results are in good concordance with a low error percentage for the two considered beams

$\checkmark$ The effectiveness of Hidden Layer Size produced more accurate results depends on the number of collected data where this analysis confirms the validity.

\section{ACKNOWLEDGEMENT}

he fourth author, Samir Khatir, acknowledges the funding of the postdoctoral fellowship BOF20/PDO/045 provided by Bijzonder Onderzoeksfonds (BOF), Ghent University.

\section{REFERENCES}

[1] Sinou, J. J. (2009). A review of damage detection and health monitoring of mechanical systems from changes in the measurement of linear and nonlinear vibrations, Mech. Vib.: Measure. Effects Control, pp. 643 -702.

[2] Yang, X.F., Swamidas, A.S.J. and Seshadri, R. (2001). Crack identification in vibrating beams using the energy method, J.Sound Vib, 244, pp. 339-357. DOI: 10.1006/jsvi.2000.3498.

[3] Swamidas, A.S.J., Yang, X. and Seshadri, R. (2004). Identification of cracking in beam structures using Timoshenko and Euler formulations, J. Eng. Mech., 130, pp. 1297-1308. DOI: 10.1061/(asce)07339399(2004)130:11(1297).

[4] Dougdag, M., Ouali, M., Mellel, N. and Attari, K. (2014). Détection de fissures dans les poutres d'acier: une nouvelle

[5] approche par balayage de mesures de vibrations, Mech. Reports, 342(8), pp. 437-449.

DOI : 10.1016/j.crme.2014.05.001.

[6] Gillich, G.R., Praisach, Z.I., Abdel Wahab, M., Gillich, N.,Mituletu, I.C. and Nitescu, C. (2016). Free vibration of a perfectly clamped-free beam with stepwise eccentric distributed masses, J. Shock Vib. DOI : 10.1155/2016/2086274. 
[7] Gillich, G.R., Furdui, H., Wahab, M.A. and Korka, Z.I. (2019). A robust damage detection method based on multimodal analysis in variable temperature conditions, Mech. Syst. Signal Process., 115, pp. 361-379.

DOI : 10.1016/j.ymssp.2018.05.037.

[8] Zhou, Y.L., Maia, N.M., Sampaio, R.P. and Wahab, M.A. (2017). Structural damage detection using transmissibility together with hierarchical clustering analysis and similarity measure, Struct. Health Monitor.,16, pp. 711-731.

DOI : $10.1177 / 1475921716680849$.

[9] Zhou, Y.L., Maia, N.M. and Abdel Wahab, M. (2018). Damage detection using transmissibility compressed by principal component analysis enhanced with distance measure, J. Vib. Control., 24, pp. 2001-2019.

DOI : $10.1177 / 1077546316674544$.

[10] Loutridis, S., Douka, E. and Hadjileontiadis, L.J. (2005). Forced vibration behaviour and crack detection of cracked beams using instantaneous frequency, J. Ndt \& E International., 38, pp. 411-419. DOI : 10.1016/j.ndteint.2004.11.004.

[11] Samir, K., Idir, Belaidi, Serra, R., Brahim, B., Aicha, A. (2015). Genetic algorithm based objective functions comparative study for damage detection and localization in beam structures. In Journal of Physics: Conference Series., 628 (1), p 012035. IOP Publishing, Damas, 24-26 August, Ghent, Belgium.

[12] Khatir S. Boutchicha D. Le Thanh C et al. (2020b). An efficient hybrid TLBO-PSO-ANN for fast damage identification in steel beam structures using IGA. Smart Structures and Systems., 25, pp. 605-617. DOI : 10.12989/sss.2020.25.5.605.

[13] Guo, H., Hamdia, K., Zhuang, X. and Rabczuk, T. (2020), An energy approach to the solution of partial differential equations in computational mechanics via machine learning: Concepts, implementation and applications, Comput. Methods Appl. Mech. Eng., 362, 112790. DOI: 10.1016/j.cma.2019.112790.

[14] Samaniego, E., Anitescu, C., Goswami, S., Nguyen-Thanh, V.M., Guo, H., Hamdia, K., Zhuang, X. and Rabczuk, T. (2020), An energy approach to the solution of partial differential equations in computational mechanics via machine learning: Concepts, implementation and applications. Comput. Methods Appl. Mech. Eng., 362, 112790. DOI: $10.1016 /$ j.cma.2019.112790.

[15] Tran-Ngoc, H., Khatir, S., Le-Xuan, T., De Roeck, G., Bui-Tien, T. and Wahab, M.A. (2020a). A novel machinelearning based on the global search techniques using vectorized data for damage detection in structures, Int. J. Eng. Sci., 157, 103376. DOI: 10.1016/j.ijengsci.2020.103376.

[16] Fayyadh, M.M., Razak, H.A. and Ismail, Z. (2011). Combined modal parameters-based index for damage identification in a beamlike structure: theoretical development and verification, J. Arch. Civil Mech. Eng., 11, pp. 587-609. DOI : 10.1016/s1644-9665(12)60103-4.

[17] Tran-Ngoc, H., Khatir, S., De Roeck, G., Bui-Tien, T. and Wahab, M.A. (2019). An efficient artificial neural network for damage detection in bridges and beam-like structures by improving training parameters using cuckoo search algorithm, Eng.Struct., 199, 109637. DOI: 10.1016/j.engstruct.2019.109637.

[18] Tran-Ngoc, H., He, L., Reynders, E., Khatir, S., Le-Xuan, T., De Roeck, G., Bui-Tien, T. and Wahab, M.A. (2020b), An efficient approach to model updating for a multispan railway bridge using orthogonal diagonalization combined with improved particle swarm optimization, J. Sound Vib., 476, 115315. DOI: 10.1016/j.jsv.2020.115315.

[19] Khatir S, Dekemele K, Loccufier M, et al. (2018) Crack identification method in beam-like structures using changes in experimentally measured frequencies and Particle Swarm Optimization. Comptes Rendus Mécanique, 346, pp. 110_ 120. DOI: $10.1016 /$ j.crme.2017.11.008.

[20] Behtani, A., Tiachacht, S., Khatir, S., Slimani, M., Mansouri, L., Bouazzouni, A. and Wahab, M. A. (2020). The sensitivity of modal strain energy for damage localization in composite stratified beam structures. In Proceedings of the 13th International Conference on Damage Assessment of Structures, pp. 863-874. Springer, Singapore.

[21] Khatir, S., Belaidi, I., Khatir, T et al. (2017). Multiple damage detection in composite beams using Particle Swarm Optimization and Genetic Algorithm. J Mechanika., 23, pp. 514-521. DOI: 10.5755/j01.mech.23.4.15254.

[22] Khatir, S., Magd, A.W. (2019). A computational approach for crack identification in plate structures using XFEM, XIGA, PSO and Jaya algorithm. Theoretical and Applied Fracture Mechanics,103, 102240. DOI: $10.1016 /$ j.tafmec.2019.102240.

[23] Khatir, S., Boutchicha, D., Le Thanh, C., Tran-Ngoc, H., Nguyen, T.N. and Abdel-Wahab, M. (2020). Improved ANN technique combined with Jaya algorithm for crack identification in plates using XIGA and experimental analysis, Theor. Appl. Fract. Mech., 107, 102554. DOI: 10.1016/j.tafmec.2020.102554.

[24] Lee, J.W., Kim, S.R. and Huh, Y.C. (2014). Pipe crack identification based on the energy method and committee of neural networks, Int. J. Steel Struct.res, 14, 345-354. DOI: 10.1007/s13296-014-2014-0.

[25] Li, D., Lu, D. and Hou, J. (2017). Pipeline damage identification based on additional virtual masses, Appl. Sci., 7, 1040. DOI: $10.3390 / \operatorname{app} 7101040$. 
[26] Seguini, M., Khatir, S., Boutchicha, D., Nedjar, D. and Wahab, M. A. (2021). Crack prediction in pipeline using ANNPSO based on numerical and experimental modal analysis. Smart Struct. Syst, 27(3), 507-523.

DOI: 10.12989/sss.2021.27.3.507

[27] Seguini, M., Khatir, S., Boutchicha, D., Nedjar, D., Waheb, M.A. (2020)experimental and numerical vibration Analyses of Healthy and Cracked Pipes. 1st International conference on structural health monitoring and engineering structures (SHM\&ES). 